\title{
COMPARATIVE ANALYSISOF AFFILIATE MARKETING PROGRAM OF FLIPKART AND AMAZONINDIA
}

\author{
Mr. Arpan Sen ${ }^{1}$, Prof. Sneha Kanade ${ }^{2}$ \\ ${ }^{1}$ MBA, Garden City University, Bangalore, India \\ ${ }^{2}$ Assistant Professor, School of Commerce and Management, Garden City University \\ Bangalore, India
}

DOI: 10.46609/IJSSER.2021.v06i04.004 URL: https://doi.org/10.46609/IJSSER.2021.v06i04.004

\begin{abstract}
Affiliate marketing has become the most important strategy for any online business. It's a framework that helps businesses to collaborate and sustain in longer run. This is basically a performance-based marketing, the more visitors or customers you provide a company, the more commission one gets. These innovative business models will create an opportunity for small businesses and individuals in generating earnings. This research article explores the affiliate marketing strategies of Amazon and Flipkart.
\end{abstract}

Keywords: Affiliate Marketing, collaboration, sustainability, online businesses.

\section{Introduction}

\section{Affiliate Marketing}

Affiliate Marketing is a model or framework in which a business rewards one or more of its affiliates for each visitor or customer brought by the affiliates own marketing efforts. Affiliates need not have to be a part of any company, they can simply search for a product online and promote the product of their choice and earn profit out of each sale made. This is basically a performance-based marketing, the more visitors or customers your provide a company, the more commission one gets.

\section{Flipkart}

Flipkart is an e-commerce company headquartered in Bangalore, Karnataka, India and registered in Singapore. It started their operation by selling books online before expanding into other product categories such as consumer electronics, fashion, home essentials, groceries and lifestyle products. It was founded in October 2007 by Sachin Bansal and Binny Bansal.

\section{Amazon}

Amazon is an American multinational technology company based om Seattle, Washington, 
which focuses on e-commerce, cloud computing, digital streaming, and artificial intelligence. It was founded by Jeff Bezos in Bellevue, Washington, on July 5, 1994. It started as an online marketplace for books but later expanded to sell electronics, software, video games, apparel, furniture, food, toys, and jewellery.

\section{Review}

Sandeep Prabhu and Tanmay Satpathy (2015) in their study "Affiliate Marketing's future in India", mention that Innovative customer acquisition programmes like affiliate marketing shall be growing extensively in coming years. Organisations should look beyond their present business models and adopt to cost effective models based on affiliate network. These innovative business models will create an opportunity for small businesses and individuals in generating earnings. Considering pace of technology, changes and innovations may come up but the conceptual base of the model will remain similar. Indian businesses and individuals can benefit from affiliate marketing in future. ${ }^{1}$

Adam Enfroy in his blog "Affiliate Marketing in 2021: What it is and how you can get started" summarised that, "Affiliate marketing is an ideal solution for those looking to gain control of their own income by focusing on performance-based revenue options. Working in tandem with a seller, a motivated affiliate marketer will be able to achieve a passive income from the comfort of their home without worrying about producing their own product or service. Although the success of the job does depend on the affiliate's marketing skills, it can prove to be an effective way to meet your income goals as either a primary career or a profitable second job. An elegantly straightforward process, affiliate marketing via reviews, blogs, social media, webinar software, and other platforms is a new frontier in marketing that's just waiting to be utilized." 2

K Francis Sudhakar and Habeeb Syed (2016) in their study "a comparative study between Flipkart and Amazon India"concluded that the innovative thinking of them to reach more and more consumers in appreciable. They increased their network as much as possible with ultimate aim of reaching more and more customers. They made consumers work more easy and comfortable. In this competitive market one has to be lead and rest will follow. Based upon consumer's survey we got our clear winner and it is Amazon. Even though it is an international company it understood Indian very well and made its roots stronger in India. Flipkart is also giving very tough competition to Amazon even though it is new company when compared to Amazon. ${ }^{3}$

KritishRules (2018) in his blog "Amazon vs Flipkart Program - Which one is better for Indians?" for Money24hr suggested that "If you want to get the best result from your affiliate marketing, it would be best if you first sign up for both and try out which one is working better 
for you. For example, you can place a few affiliate links from both Amazon and Flipkart on your website for a few months and test out which one has a higher conversion rate. Currently, Amazon affiliate program looks like a better alternative over Flipkart because of its excellent affiliate facilities. Flipkart needs a little improvement in transparency, tracking and reflecting commission reports. ${ }^{4}$

Kanuj (2020) in his blog "Flipkart vs Amazon India Affiliate Program - Which is better?" for Profound Blogger stated that, "These are excellent to earn additional income from your blog or website or even your Youtube Channel. Since there no other options as most other affiliate programs are already closed these are a must-try for bloggers. Considering that Indian content creators have very limited choices to make money the large companies may be exploiting the situation. We have seen several orders are removed at a later date that otherwise would have helped creators earn a lot more commission. There is no transparency about cancelled orders and why certain orders were removed from final commissions paid to creators. The commissions are now paid on the product value - GST, which created nearly $20 \%$ dent in the earnings."5

\section{Objectives}

1. To understand the differences in the affiliate marketing programs of Flipkart and Amazon

2. To know which company is doing better among the affiliates.

3. To find out the opportunities and options of earning revenues provided by the respective programs

\section{Methodology}

This study is concerned with the comparative analysis of affiliate marketing programs of Flipkart and Amazon India. The secondary research method is being used to conduct this particular study.

Secondary Research is a research method that involves using already existing data. Existing data is summarized and collated to increase the overall effectiveness of the research. Secondary research includes research material published in research reports and similar documents.

Various websites, articles, and blogs were referred to collect the necessary amount of information, as well as check the authenticity of the information about the study.

\section{Results}

Comparisons are done on the basis of:

\section{Commissions}

Flipkart

(Flipkart.com) 
International Journal of Social Science and Economic Research

ISSN: 2455-8834

Volume:06, Issue:04 "April 2021"

\begin{tabular}{|l|l|l|}
\hline CATEGORY & New Customer & Existing Order \\
\hline Grocery & $18 \%$ & $3 \%$ \\
\hline Furniture & $10 \%$ & $8 \%$ \\
\hline Laptop & $8 \%$ & $8 \%$ \\
\hline Fashion \& Lifestyle & $4 \%$ & $4 \%$ \\
\hline Electronic Devices \& Accessories & $5 \%$ & $5 \%$ \\
\hline Large Appliances & $4 \%$ & $4 \%$ \\
\hline Small Home Appliances & $8 \%$ & $8 \%$ \\
\hline Books \& General Merchandise & $5 \%$ & $4 \%$ \\
\hline Home & $5 \%$ & $4 \%$ \\
\hline All Mobile Phones & $1 \%$ & $1 \%$ \\
\hline
\end{tabular}

\section{Commissions (Amazon India)}

\begin{tabular}{|l|l|}
\hline CATEGORY & Existing Order \\
\hline Kitchen Appliances & $9 \%$ \\
\hline Furniture & $9 \%$ \\
\hline Grocery & $8 \%$ \\
\hline Home, baby & $6 \%$ \\
\hline Automotive, lawn \& garden, sports & $6 \%$ \\
\hline Consumer electronics \& accessories & $5 \%$ \\
\hline Large Appliances & $5 \%$ \\
\hline Books, office products, industrial \& scientific products & $5 \%$ \\
\hline Apparel \& accessories & $5 \%$ \\
\hline Health, beauty and personal care & $5 \%$ \\
\hline Jewellery & $5 \%$ \\
\hline Mobile accessories, musical instruments & $4 \%$ \\
\hline
\end{tabular}


International Journal of Social Science and Economic Research

ISSN: 2455-8834

Volume:06, Issue:04 "April 2021"

\begin{tabular}{|l|l|}
\hline Bicycles \& heavy gym equipment & $2.5 \%$ \\
\hline Data storage devices & $2 \%$ \\
\hline Mobile phones & 15 \\
\hline Gold \& silver coins & $0.2 \%$ \\
\hline All other categories & $5 \%$ \\
\hline
\end{tabular}

\section{Ease of Joinin}

Flipkart

Its pretty easy to join the Flipkart affiliate program. For joining one need to go to the affiliate program page of Flipkart and click on "Join for free". Then, one will be guided to the registration page.

Amazon

Joining Amazon's Affiliate Program or Amazon's Associates is also pretty easy, simple and free to join. Alike Flipkart one can go to the Affiliate or Associates page of amazon and then sign up with the program.

\section{Tools}

Flipkart

(Flipkart.com)

Flipkart provides extensive range of tools for the affiliates to work with. The tools provided are:

1. Product links and banners

2. Promotional banners and widgets

3. Search tools

\section{APIs}

The tools are also very well explained in the website.

Amazon (Amazon India)

Alike Flipkart, Amazon have also provided various tools with detailed explanation about each of them.

The tools provided are:

1. SiteStrips 
2. Product Links

3. Banners

4. APIs

\section{Reports and Tracking}

Both Flipkart and Amazon provide affiliates with detailed report. One will be able to track the number of visits, clicks, product orders and commissions on daily basis. But, many sources have stated that Flipkart's reports are sometimes not correct and have errors. Whereas, Amazon's reports are always correct and accurate.

Amazon provides affiliates with the following types of reports: (Amazon India)

1. Earnings

2. Orders

3. Link-Type

4. Daily Trends

5. Tracking ID Summary

6. Payment History

Unlike Amazon, to know about Flipkart's reporting structure and types offered one has to sign up with the program to know the details.

\section{Payment Options (Digital Dhairya)}

Affiliates will have to submit their bank details like name, account number, and IFSC code to receive the payments from either companies. Both companies also provide affiliates with the flexibility of changing their account details as of their wish.

Affiliates will also have to submit their Pan card details for taxation purposes. However, they can file a refund for the tax deducted by Flipkart or Amazon at the time of filing the income tax return.

\section{Flipkart}

They provide affiliates with the following payment options:

1. Gift Vouchers 
International Journal of Social Science and Economic Research

ISSN: 2455-8834

Volume:06, Issue:04 "April 2021"

Flipkart withholds referral fees until the affiliates' reach an amount of ₹2500. The gift vouchers can be redeemed against the purchase from Flipkart.

\section{Electronic Fund Transfer (EFT)}

The payment threshold in case of EFT is ₹ 5000

Flipkart process the payments once the product is received by the buyer and after the cancellation or return timeframe is exhausted, if any. Such as, Flipkart offers 30 day cancellation or return policy to its buyers, on some products. So, the payments for such purchases will be made after 30 days from the day when an order was made.

In case Flipkart owes their Affiliate partners less than ₹ 2500 of gift voucher and ₹ 5000 in case of EFT, then it is likely that they will process the balance it in the subsequent month.

Flipkart does not charge any fee on any of the payment options. However, they deduct 5\% TDS for all the payments made through EFTs and also on Gift Vouchers. If any affiliate does not provide PAN then Flipkart deducts $20 \%$ TDS.

\section{Amazon}

Their affiliate program pays affiliate on a monthly basis, that means, affiliates receive the payment or the advertising fees in approx. 60 days or after the end of each month.

Unlike Flipkart, Amazon's Affiliate program has payment options of Cheque and National Electronic Fund (NEFT). If affiliates' have chosen the cheque option then the cheque is usually sent to their registered address.

In case of NEFT, the associate program will not process the payment until the associates meet the threshold of ₹ 1000 . In case of cheque, amazon does not send you the payment until the outstanding is at least ₹2500.

Amazon Associate Program does not charge VAT on any earnings through the program. Also, there are no deductions if there are order cancellations, refund or returns etc.

\section{Conclusion}

Based on the comparative study it is evident that Amazon's Affiliate Program is better than Flipkart's. Flipkart is an Indian company as well as entering the Indian market way before Amazon came, has failed to build strong roots among the people interested to be affiliates. Amazon is better than Flipkart in commission payout. They also have a better commission structure. Amazon's payment policies and options are also better than Flipkart's. Due to all this, people with good marketing skills can earn more through Amazon's program than Flipkart's. 


\section{International Journal of Social Science and Economic Research}

ISSN: $2455-8834$

Volume:06, Issue:04 "April 2021"

Amazon has also presented its reporting and tracking structure and types, which is easily accessible to the prospect affiliates and other stakeholders. On the other hand, Flipkart has not done the same, to know about their reporting structure one has to sign up with their program. Moreover, as per sources, Flipkart is not that accurate and good at presenting the reports to the affiliates and often has mistakes. Whereas, Amazon have not disappointed their affiliates.

A point to be noted is that, instead of all this, Flipkart has a better conversion rate than Amazon, which is due to its origins as Indians feel more comfortable using a home-grown brand than a foreign one. However, Amazon is slowly gaining traction in the market and also building up affinity among Indian users. Especially because of their introduction in other sectors such as Amazon Prime and Amazon Studios in the entertainment sector.

Nevertheless, Amazon is the clear winner and is expected to grow more in the Indian market. Flipkart is now owned by the American retailer, Walmart. This acquisition might bring some change in the way Flipkart operates now, may pose a great threat to Amazon. However, for the time being, Amazon is doing great to satisfy the affiliates and Flipkart is doing great in satisfying their customers.

\section{References}

Amazon India. (2021). Advertising Fee Schedule: Amazon Associates. Retrieved from Amazon Associates:

https://affiliateprogram.amazon.in/help/operating/schedule/ref=amb_link_1WE1Uz6ISLayK8hZdE_Jxg_4?pf_r d_p=a4f3c8dd-3ab1-4aca-b960-dd602e857962

Amazon India. (2021). Topic: Reports. Retrieved from Amazon Associate Program: https://affiliate-program.amazon.in/welcome/topic/reports

Amazon India. (2021). Topic: Tools. Retrieved from Amazon Associates: https://affiliateprogram.amazon.in/welcome/topic/tools

Digital Dhairya. (2019, February 18). Retrieved from Digital Dhairya: https://digitaldhairya.com/flipkart-vs-amazon/

Enfroy, A. (2020). Blog: Affiliate Marketing. Retrieved from Bigcommerce: https://www.bigcommerce.com/blog/affiliate-marketing/\#how-does-affiliate-marketing-work

Flipkart.com. (2021). Commissions. Retrieved from Flipkart Affiliate: https://affiliate.flipkart.com/commissions

Flipkart.com. (2021). Tools: Affiliate Tools Info. Retrieved from Flipkart Affiliate: https://affiliate.flipkart.com/tools/affiliate-tools-info 
International Journal of Social Science and Economic Research

ISSN: 2455-8834

Volume:06, Issue:04 "April 2021"

Kanuj. (2020, May 26). Blogging. Retrieved from Profound Blogger: https://profoundblogger.com/flipkart-vs-amazon-india-affiliate-program/

Kritish. (2018, October 23). Blog. Retrieved from Money 24hr: https://money24hr.com/amazonvs-flipkart-affiliate-program/

Prabhu, S., \& Satpathy, T. (2015, February). Affiliate Marketing's Future in India. Retrieved from https://sciresol.s3.us-east-2.amazonaws.com/IJST/Articles/2015/Issue-Supplementary4/Article34.pdf

Sudhakar, K. F., \& Habeeb, S. (2016, September). Retrieved from http://publications.anveshanaindia.com/wp-content/uploads/2016/09/A-COMPARATIVESTUDY-BETWEEN-FLIPKART-AND-AMAZON-INDIA.pdf 